\title{
Research of the Effect of Different Dosage of Grinding Aids on Properties and Process Parameters of Steel Slag Power
}

\author{
Qin Yumin \\ Bao Wu Group Environmental Resources Technology Co., Ltd, Shanghai, China \\ Email address: \\ qinyumin $@$ baosteel.com \\ To cite this article: \\ Qin Yumin. Research of the Effect of Different Dosage of Grinding Aids on Properties and Process Parameters of Steel Slag Power. \\ American Journal of Materials Synthesis and Processing. Vol. 3, No. 2, 2018, pp. 34-38. doi: 10.11648/j.ajmsp.20180302.15
}

Received: May 30, 2018; Accepted: September 1, 2018; Published: September 26, 2018

\begin{abstract}
Because of the high hardness and poor wear resistance of steel slag, the potential cementing property of steel slag can not be effectively exerted, and the utilization rate of steel slag. Is low. In order to improve the performance and grinding efficiency of steel slag powder, different grinding aids were added in the process of steel slag grinding in laboratory and production line respectively. The effects of different grinding aids on the performance and technological parameters of steel slag powder were studied. The results show that the specific surface area of steel slag powder is higer or lower, the fluidity and the activity index increased, the energy consumption of ball mill is reduced, the energy consumption of elevator and separator increased. The following conclusions can be drawn: (1) Steel slag properties: different grinding aids have no obvious effect on the grinding fineness of steel slag powder, but can effectively improve the activity index of steel slag powder. (2) Technological parameters: different dosage of grinding aids can reduce the power consumption of ball mill and improve the energy power consumption of elevator and separator. With the increase of dosage, the process parameters will be greatly affected, so the amount of grinding aids should be effectively controlled.
\end{abstract}

Keywords: Grinding Aids, Steel Slag Powder, Quality Characteristics, Process Parameters

\section{Introduction}

China is the largest producer of steel in the world [1]. According to the statistics of National Bureau of statistics, the cumulative output of crude steel increased by $5.7 \%$ in 2017 , reaching 831 million 730 thousand T [2]. Steel slag is a by-product of iron and steel production, The yield is about $10 \%$ $\sim 15 \%$ of the coarse steel [3]. At present, the comprehensive utilization rate of steel slag in China is about $50 \%$ to $60 \%$ [4], but only about $10 \%$ in building materials [5]. China's $70 \%$ steel slag is a converter steel slag with similar chemical composition and silicate clinker, and has potential cementitious properties [6]. The utilization rate of steel slag is relatively low. The main reason is that the steel slag has poor abrasive wear and high grinding energy consumption.

In recent years, with the attention paid by the cement and concrete industry to the saving, consumption and emission reduction, the slag powder made from steel slag has begun to be used as the active mineral admixture in the production of cement concrete [7]. And the research of steel slag grinding aids is becoming more and more. The traditional grinding aids can be divided into liquid grinding aids and solid grinding aids. Most of their basic components belong to organic surfactant. They are mainly amines, alcohols, ethanolamines, lignosulfonic salts, fatty acids and their salts, alkyl sulfonates, etc [8-11]. Qin yumin found that different grinding aids can help the grinding of steel slag in Baosteel [12]. It can improve the effect of the specific surface area to the activity index, and the setting time has some influence, which can reduce the energy consumption of the production. Cheng zhou found that the optimization effect of grinding agent on the grain size of steel slag is mainly within $30 \mathrm{~min}$, and it can improve the strength activity index of steel slag and reach the standard of C type fly ash [13]. Wu Gang, Li Weifeng, Liusi, Joseph J, Zhu $\mathrm{Xi}$ and other studies show that the specific surface area, the activity index and the cementitious activity of steel slag with the grinding agent are improved with the addition of the grinding agent [14-18]. There is a lot of analysis on the influence of grinding aids on the grinding properties of steel slag in the laboratory, but there is still a big gap between the 
test room environment and the large production. Some arguments still need to be tested in practice.

In this paper, the application effect of the same kind of grinding aids was tested under the test room and the actual production conditions. The double circulation grinding system of Shanghai Baosteel New Building Materials Technology Co., Ltd. was used, and the properties of the products were studied by the quality characteristics and technological parameters of the products. Influence of grinding process parameters.

\section{Raw Materials and Test Methods}

\subsection{Raw Materials}

Steel slag: taken from Shanghai Baoshan Iron and Steel Group, its chemical analysis data are shown in Table 1.

Cement: reference cement specified in GB 8076-2008 "concrete additive".

Grinding aids: ZM provided by A company.

Standard sand: GB/T 17671-1999 standard sand specified in "strength test method for cement mortar".

Mix water: tap water.

Table 1. Chemical composition of steel slag $/ \%$.

\begin{tabular}{lllllllll}
\hline $\mathbf{A l}_{2} \mathbf{O}_{3}$ & $\mathbf{M g O}$ & $\mathbf{F e}_{2} \mathbf{O}_{\mathbf{3}}$ & $\mathbf{S O}_{3}$ & $\mathbf{M n O}$ & $\mathbf{C a O}$ & $\mathbf{S i O}_{2}$ & $\mathbf{S}$ & $\mathbf{P}_{2} \mathbf{O}_{\mathbf{5}}$ \\
\hline 1.38 & 9.94 & 28.17 & 0.70 & 1.86 & 43.73 & 12.07 & 0.037 & 2.14 \\
\hline
\end{tabular}

\subsection{Test Methods}

\subsubsection{Addition of Grinding Aids, Sampling of Steel Slag Powder and Testing of Physical Properties}

The same batch of stable steel slag was used for grinding test, and the output of ZM1 was $0.05 \%, 0.06 \%, 0.075 \%$ of the output of $34 \mathrm{t} / \mathrm{h}$. The steel slag was directly added before the ball mill was sent to the ball mill. After running $2 \mathrm{~h}$, the physical properties of the powder were tested.

\subsubsection{Determination of Properties of Steel Slag Powder}

(1) The specific surface area was determined according to GB/T 8074-2008 method for determination of specific surface area of cement.

(2) The determination of water consumption, setting time and stability of the standard consistency of slag powder-cement is carried out according to $\mathrm{GB} / \mathrm{T}$ 1346-2011 "test method for water consumption, setting time and stability of cement standard consistency".

(3) The strength of mortar is determined according to GB/T 17671-1999 test method for strength of cement mortar.

(4) Determination of activity index and fluidity ratio of steel slag powder according to GB/T 20491-2006 steel slag powder used in cement and concrete.

\section{Test Results and Analysis}

The influence of $0.1 \%$ admixture grinding aid $\mathrm{ZM}$ on the performance of steel slag powder was tested in the laboratory. The test data are shown in Table 2.

Table 2. Comparison of flow rate of mortar and activity index of steel slag powder in laboratory.

\begin{tabular}{|c|c|c|c|c|c|c|c|c|c|}
\hline \multirow{2}{*}{ Number } & \multirow{2}{*}{$\begin{array}{l}\text { Specific surface area of } \\
\text { steel slag powder } / \mathrm{m}^{2} \cdot \mathrm{kg}^{-1}\end{array}$} & \multirow{2}{*}{$\begin{array}{l}\text { Dosage of } \\
\text { grinding aids/\% }\end{array}$} & \multirow{2}{*}{ Fluidity/mm } & \multicolumn{3}{|c|}{ compressive strength/ MPa } & \multicolumn{3}{|c|}{ Active index/\% } \\
\hline & & & & 3d & $7 d$ & 28d & 3d & $7 d$ & 28d \\
\hline Cement mortar * & & - & 215 & 21.0 & 38 & 53.4 & 100 & 100 & 100 \\
\hline GZ2 & 445 & - & 212 & 7.0 & 25.8 & 43.3 & 33 & 68 & 81 \\
\hline GZ11 & 404 & 0.1 & 215 & 9.7 & 25.8 & 45.4 & 46 & 68 & 85 \\
\hline GZ21 & 440 & 0.1 & 214 & 8.2 & 25.8 & 47.0 & 39 & 68 & 88 \\
\hline
\end{tabular}

Note: GZ1 is a small mill grinding $45 \mathrm{~min}$ slag powder in the test room, GZ2 is a small grinding powder of $60 \mathrm{~min}$ steel slag powder in a test room, GZ11 is a small grinding $45 \mathrm{~min}$ steel slag powder with $0.1 \%$ grinding aids, and GZ21 is a small grinding slag powder of small grinding mill with $0.1 \%$ grinding aids.

*Cement mortar is used for calculating the activity index of steel slag powder and made of pure cement.

It is visible from table 2,

(1) Specific surface area. In the laboratory, the specific surface area of the slag powder with $0.1 \%$ grinding aids is more than that of the non admixture, and the specific surface area of the GZ11 adding grinding agent is $10 \mathrm{~m}^{2} / \mathrm{kg}$ and the GZ21 specific surface area of the admixture is $5 \mathrm{~m}^{2} / \mathrm{kg}$ lower than that of the non admixture, and the surface area of the additive is lower than that of the non admixture GZ2.

(2) Intensity activity index. The $28 \mathrm{~d}$ intensity activity index of the steel slag powder mixed with $0.1 \%$ grinding aids in the laboratory is higher than that of the non doped agent. The GZ11 intensity activity index of the grinding aids increased by $5 \%$ compared with that of the non doped GZ1, and the GZ21 activity index of the grinding aids increased by $7 \%$ compared with that of the non doped GZ2.

The quality characteristics and technological parameters of the steel slag powder after grinding were compared and analyzed. The quality characteristics include the specific surface area and the intensity activity index of the steel slag powder. 


\subsection{Effect of Different Dosage of Grinding Aids on the Specific Surface Area and Grinding Efficiency of Steel Slag Powder}

Table 3 shows the specific surface area of steel slag powder produced by grinding with different amounts of grinding aids.

Table 3. Comparison table of specific surface area of slag powder.

\begin{tabular}{lllll}
\hline Number & Kinds of grinding aids & Dosage of grinding aids / $\%$ & Grinding time & $\begin{array}{l}\text { Specific surface area of steel } \\
\mathbf{s l a g}_{\mathbf{p o w d e} / \mathbf{m}^{2} . \mathbf{k g}^{-1}}\end{array}$ \\
\hline A0 & - & - & $8: 00 \sim 9: 50$ & 435 \\
A1 & ZM & 0.05 & $9: 50 \sim 12: 50$ & 440 \\
A2 & ZM & 0.075 & $12: 50 \sim 13: 20$ & 435 \\
A3 & ZM & 0.06 & $13: 20 \sim 15: 30$ & 435 \\
\hline
\end{tabular}

It is visible from table 3 ,

In actual production, the specific surface area of the slag powder containing ZM is different from that in the test room, and there is no obvious change, even a downward trend, compared with those in the non admixture.

\subsection{Effect of Different Dosage of Grinding Aids on Fluidity and Activity of Steel Slag Powder Sand}

Under the same water binder ratio, the steel slag powder obtained by grinding is equivalent to $30 \%$ cement instead of the same cement. The fluidity and intensity activity index of the mortar are tested, and the results are shown in Table 4.

Table 4. Comparison of fluidity of mortar and activity index of steel slag powder.

\begin{tabular}{|c|c|c|c|c|c|c|}
\hline \multirow{2}{*}{ Number } & \multirow{2}{*}{ Dosage of grinding aids/\% } & \multirow{2}{*}{ Fluidity /mm } & \multicolumn{2}{|c|}{ compressive strength/ MPa } & \multicolumn{2}{|c|}{ Intensity active index/\% } \\
\hline & & & $7 d$ & 28d & $7 d$ & 28d \\
\hline Cement mortar * & - & 215 & 38 & 53.4 & 100 & 100 \\
\hline MA0 & - & 212 & 24.7 & 42.7 & 65 & 80 \\
\hline MA1 & 0.05 & 215 & 27.4 & 47.0 & 72 & 88 \\
\hline MA2 & 0.075 & 216 & 27.0 & 47.5 & 71 & 89 \\
\hline MA3 & 0.06 & 214 & 27.4 & 47.0 & 72 & 88 \\
\hline
\end{tabular}

*Cement mortar is used for calculating the intensity activity index of steel slag powder and made of pure cement.

It is visible from table 4 ,

(1) Compared with the flow degree data of the blank MA0 group, the flow degree of the slag powder obtained by the grinding agent grinding is increased to a certain extent, and the increase of MA2 is the most obvious (the flow degree of $0.075 \%$ grinding aids is increased by $1.9 \%$ than that of the non admixture). The increase of fluidity of mortar is due to the dispersion of fine particles in steel slag powder. Because of the effect of grinding aids, the proportion of fine particles in the slag powder obtained by grinding is larger. The fine slag powder particles will quickly adsorb on the surface of cement particles when mixed with water and hinder the formation of the flocculation structure of the cement slurry. Furthermore, the fine slag powder particles are filled in the accumulation of cement particles, which can help to open the cement particles and improve the fluidity of the slag powder - cement mortar.

(2) compared with the steel slag powder obtained without grinding aid powder grinding, the activity index of steel slag powder mixed with grinding agent powder was improved, while the $7 \mathrm{~d}$ and $28 \mathrm{~d}$ activity index of MA2 group were increased by 6 and 9 percentage points respectively.

\subsection{Effect of Different of Dosage of Grinding Aids on Process Parameters of Steel Slag Grinding}

The grinding process is shown in Figure 1. The steel slag is pulverized into the slag powder through the pre grinding cycle system (the first pressure of the roller press), and is fed into the slag powder by the hoist to the intake port. The fine powder is finished under the collection of the dust collector, and the coarse powder is returned to the mill to be continued to be grinded. Therefore, the current of the pulverist, the ball mill current and the external circulation hoist are 3 important parameters to measure the operation condition of the process.

When the raw material is the same, the feed volume is $34 \mathrm{t} / \mathrm{h}$ and the production is stable, the grinding aids are added to the ball mill before grinding. The addition and adding time are shown in Table 5.

Table 5. addition time and addition amount of ZM grinding aids.

\begin{tabular}{llll}
\hline Grinding time & $\mathbf{9 : 5 0} \sim \mathbf{1 2 : 5 0}$ & $\mathbf{1 2 : 5 0} \mathbf{1 3 : 2 0}$ & $\mathbf{1 3 : 2 0 \sim 1 5 : 3 6}$ \\
\hline Dosage of grinding aids $/ \%$ & 0.05 & 0.075 & 0.06 \\
\hline
\end{tabular}




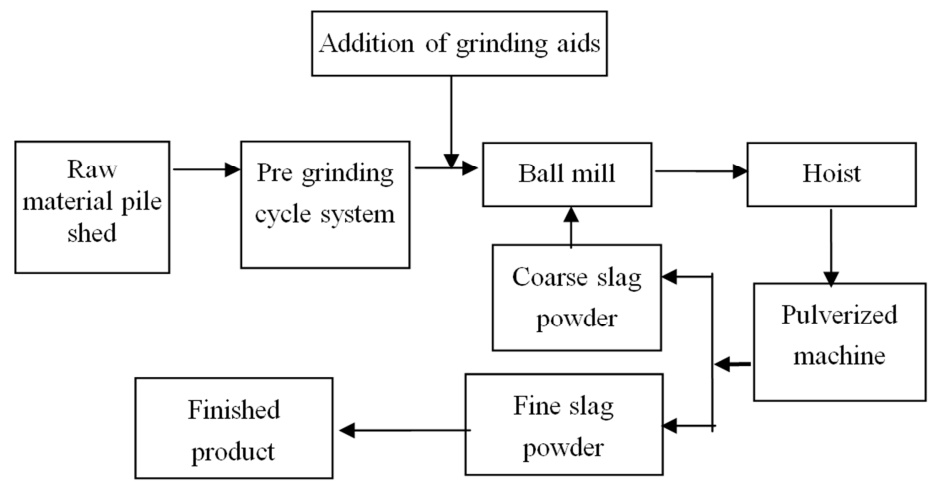

Figure 1. Process flow chart of slag grinding production.

\subsubsection{Influence of Different Dosage of Grinding Aids on the Electric Consumption of Ball Mill}

The data of ball mill current, outer loop hoist current and separator current are shown in figures 2, Figure 3, and Figure 4.

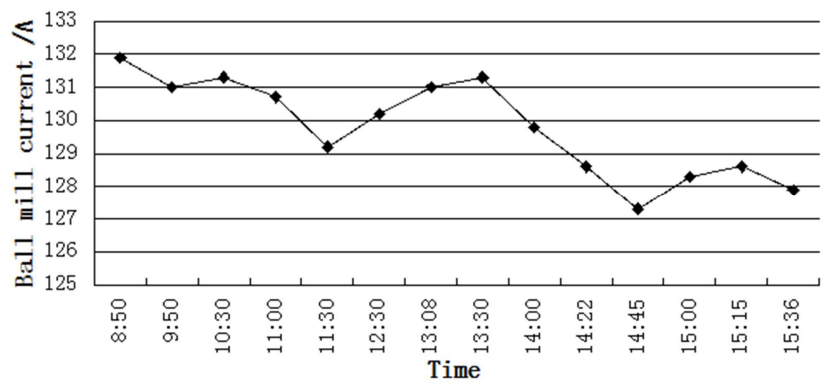

Figure 2. Current trend diagram of ball mill.

Note: the electricity consumption data at $8: 50$ is not added to the grinding agent.

From Figure 2, the current of ball mill is decreased and the flow velocity inside mill is accelerated after adding grinding aids. When the dosage of grinding aids is $0.05 \%$, the current of the ball mill is more stable. The flow degree of the material in the ball mill increases and the velocity of the ball mill increases. The electric consumption of the ball mill is reduced, and the power consumption of the ball mill is reduced by $3.03 \%$ when the dosage of the grinding agent is $0.06 \%$.

\subsubsection{The Influence of Different Dosage of Grinding Aids on the Power Consumption of the Hoist.}

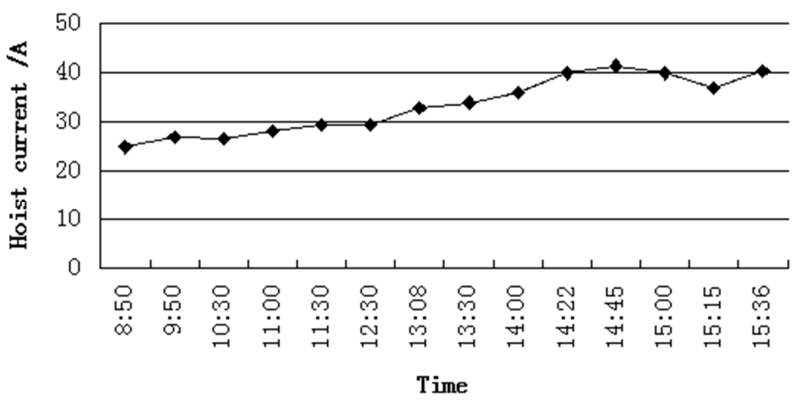

Figure 3. The current trend diagram of the hoist.

Note: the electricity consumption data at $8: 50$ is not added to the grinding agent.
As can be seen from Figure 3, with the addition of grinding aids, the current of the hoist increases with the increase of the dosage, and the material circulation increases and the load increases. The power consumption of the hoist increased by $66 \%$ when the grinding aids were added to $0.06 \%$.

\subsubsection{Influence of Different Dosage of Grinding Aids on Power Consumption of Powder Separator}

From Figure 4, it can be seen that the current of the pulverized machine is on the rise after adding the grinding aids, and the mechanical and electrical consumption of the powder selection is more stable after adding $0.05 \%$ of the grinding aids. With the increase of the amount of mixing, the material in the powder separator is increased.

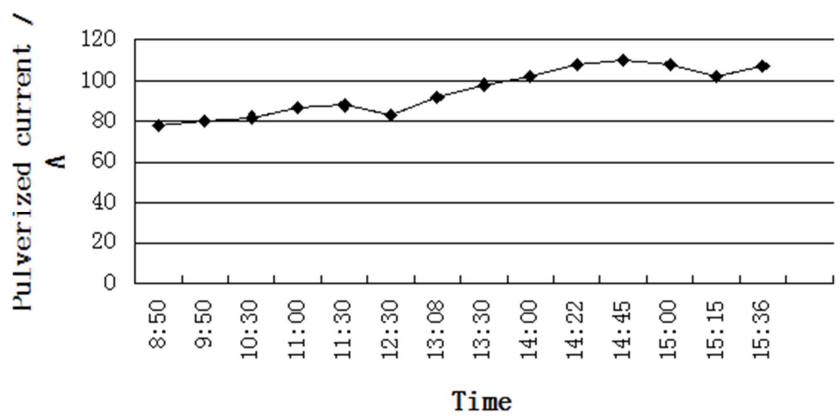

Figure 4. Current trend diagram of pulverized machine.

The volume of the finished product is coarse, the volume and speed of the coarse material increase, and the milling machine even appears the phenomenon of running ash.

\section{Conclusion}

(1) The influence of the grinding agent on the grinding fineness of the slag powder in the test room is not obvious, the $28 \mathrm{~d}$ intensity activity index is increased and the $0.1 \%$ grinding aids is increased by $7 \%$.

(2) The influence of different dosage of grinding aids on the grinding fineness of steel slag powder is not obvious in the pilot test. With the increase of the content, the intensity activity index of the slag powder is improved, and it is improved with the increase of the content of the slag. 
(3) with different grinding aids, the power consumption of ball mill is reduced, and the power consumption of hoist and separator is improved. With the increase of the dosage, the process has great influence. When the content is $0.075 \%$, the production is difficult to control.

(4) grinding aids; in the production process, we should preliminarily determine the content of the mixture through the laboratory, and then carry out the production line test to determine a reasonable amount.

\section{References}

[1] Morfeldt J, Nijs W, Silveira S. "The impact of climate targets on future steel production-an analysis based on a global energy system model" [J]. Journal of Cleaner Production, 103: pp. 469-482, 2015.

[2] Huang tao, "Discussion on the evolution trend and development form of China's iron and steel industry in the middle and long term," $[\mathrm{J}]$. Steel \& Managemen, Beijing, China, pp. 4-12, February, 2018.

[3] Jiang yuxiang, "Steel slag treatment technology and comprehensive utilization in the new area of Maang steel" [J]. Iron \& Steel, Beijing, China, Vol. 46, pp. 89-92, October, 2011.

[4] Shi huisheng, Huang kunsheng, Wu kai, Guo xiaolu. "Research advance on activition and mechanism of steel slag aciviity" [J]. Fly Ash Comprehensive Utilization, Shijiazhuang, China, pp. 48-53, February, 2011.

[5] Chen yimin, Zhanghongtao, Guosuihua, "Study on grinding fine slag powder as cement active mixture" [J]. Cement, Beijing, China, pp. 1-4, October, 2001.

[6] Xiao qizhong, Qian guangren. "Hydrothermal reaction of steel-slag in autoclave curing" [J]. JOURNAL OF THE CHINESE CERAMIC SOCIETY, 27: pp. 427-435, China, August, 1999.

[7] Li weifeng, "Study on physical and chemical properties and resource utilization of converter steel slag" [D]. Beijing University of Chemical Technology, Beijing, China.

[8] Zhu yuegang, Li canhua, Cheng yong. "Study on the Steel-slag Powder of WISCO Used as a Kind of Blending Material for Cement" $[J]$, Guangdong Chemical Industry, pp. 59-62, Guangzhou, China, November, 2005.
[9] Zhu guilin. "Present situation and development of comprehensive utilization of solid wastes in China's iron and steel industry" [J]. IRON \& ST EEL SARAP, pp. 34-41., June, 2003.

[10] Zhu ming, Hu shuguang, Ding qingjun."Investigation on Applying Steel Slag to Cementbased Materials" [J]. Journal of Wuhan University of Technology, pp: 48-51, June, 2005.

[11] Zhu lizan, Chen huaicheng, Xia zongyan, Zhao hongyi. "Development status and trend of cement grinding aids at home and abroad [J]. Chinese cement, pp. 64-66, Beijing, China, June, 2010.

[12] Qin yumin, Sunzhenping. "Research of the effect of different grinding aids on grinding and performance of steel slag power" [J], Fly Ash Comprehensive Utilization, Shijiazhuang, China, pp. 30-32, February, 2013.

[13] Cheng zhou, Li qin, Tao dejing, Tao changliang, Zhai jianping, "Study on grinding effect of steel slag grinding aids" [J]. Cement grinding aid, Beijing, China, pp. 28-31, April, 2013.

[14] Wu gang. "Influence to Grinding fineness of Steel Slag with different grinding agent" [J]. Non-metallic Mines, Suzhou, China, vol. 36, pp. 45-47, Feburay, 2012.

[15] Li weifeng, Ma suhua, zheng jiaoling, Shen xiaodong, Zhong baiqian, "Effect of grinding aids on grinding and properties of converter slag" [J]. Concrete, Shenyang, China, vol. 270, pp. 34-40, August. 2012.

[16] Liu si, Li canhua. "Experimental study on selectivity of grinding aids for steel slag" [J]. Wuhan Iron and Steel Corporation Technology, Wuhan, China, pp. 18-20, 42, Feburary, 2011.

[17] Joseph J. Assaad Camille A. Issa. "Effect of clinker grinding aids on flow of cement-based materials" [J]. Cement and Concrete Research, Vol. 63, pp. 1-112014, 63: 1-11, September, 2014.

[18] Zhu Xi, Hou Haobo, Huang Xuquan, Zhou MinWang, Wei xing, "Enhance hydration properties of steel slag using grinding aids by mechanochemical effect" [J]. Construction and Building Materials, Vol. 29, pp. 476-481, April, 2012. 